\title{
Portal Hemodynamics in Hyponatremic Egyptian Cirrhotic Patients
}

\author{
Shimaa A Awwaad', Elsaid G Elbadrawy', Hala IM Hussein', \\ Ahmed S Mohammed ${ }^{1}$, Walaa M Samy ${ }^{2}$, Ayman F Zeid ${ }^{3}$. \\ ${ }^{1}$ Tropical Medicine Department, Faculty of Medicine, Zagazig University, Zagazig, Egypt. \\ ${ }^{2}$ Medical Biochemistry Department, Faculty of Medicine, Zagazig University, Zagazig, Egypt. \\ ${ }^{3}$ Radiology Department, Faculty of Medicine, Zagazig University, Zagazig, Egypt.
}

Corresponding Author Shimaa A Awwaad

Mobile:
01128205565
Email:
shimaaawad2013@gm
ail.com

Short title:

Key words:

Hyponatremia, Portal hypertension, Portal hemodynamics, Portal vein $(P V)$, Portal vein congestive Index $(P V$ CI), Hepatic Artery resistive Index (hepatic A RI)
Background and study aim: In cirrhotic patients, portal hemodynamics is associated with hyponatremia. So, we aimed to assess portal hemodynamic changes in hyponatremic Egyptian cirrhotic patients.

Patients and Methods: one hundred and sixty cirrhotic patients due to viral causes with or without bilharziasis were included in the study, 125 males and 35 females with mean age of 50.7 years. Patients were divided into 2 groups, Group I 80 hyponatremic patients with serum $\mathrm{Na}<130 \mathrm{mmol} / \mathrm{L}$ and group II 80 Non hyponatremic patients with serum $\mathrm{Na}>130 \mathrm{mmol} / \mathrm{L}$. All patients were exposed to full history taking, clinical examination, laboratory investigations, abdominal ultrasonography (US) with Doppler study of portal circulation and upper GIT endoscopy and followed during their stay in hospital.

Results: Serum sodium had a statistically significant positive correlation with mean portal vein $(\mathrm{PV})$ velocity $(\mathrm{r}=0.252, \mathrm{p}=$ 0.001) and a highly statistically significant negative correlation with Mean flow volume, portal vein congestive index (PVCI) and hepatic artery resistive index(Hepatic A RI) $(\mathrm{r}=-0.593, \mathrm{r}=$ 0.477 and, $r=-0.490$ respectively with $\mathrm{p}<$ 0.001 for all). Analysis of the receiver operating characteristic (ROC) curve revealed that portal vein congestive index was the most sensitive indicator and hepatic artery resistive index was the most specific indicator for prediction of mortality in hyponatremia patients. MELD-Na score was the most sensitive indicator and portal vein congestive index was the most specific indicator for hepatic encephalopathy prediction in hyponatremia patients.

Conclusion: Hyponatremic patients had statistically significant portal hemodynamic changes with increased morbidity and mortality in them.

\section{INTRODUCTION}

Decompensated cirrhotic patients usually have severe complications which have great impact on the progression of cirrhosis and consequently on their quality of life [1]. "Hyponatremia in patients with cirrhosis is demarcated as serum sodium level less130 mEq/L". It is a common finding in cirrhotic patients, and usually associated with multiple clinical manifestations and a poor prognosis [2, 3]. Pathophysiology of hyponatremia is related mainly to the abnormalities in systemic hemodynamics that is attributed to defect in the renal capacity to excrete solute-free water which leads to retention of water that is disproportionate to the retention of sodium. So, this leads to decrease in serum sodium level and hypoosmolality. Non-osmotic hypersecretion of arginine vasopressin is considered the main pathogenic factor responsible for hyponatremia $[4,5]$. As the systemic circulation may be affected by portal hypertension due to the increased intrahepatic resistance, the hyperdynamic state and the formation of collateral vessels, this suggests a close relation between hyponatremia and portal hemodynamics $[\mathbf{1 , 6}]$. 
Doppler ultrasound (US) permits the real-time examination of blood flow under physiological settings. The usefulness of this technique has been testified by many investigators for assessing portal hemodynamics in cirrhosis patients. It is harmless, easily obtained, and inexpensive $[\mathbf{7}, \mathbf{8}]$. However, there are no sufficient studies about the relationship between the combined influence of both portal parameters determined by Doppler US and hyponatremia on the prognosis of cirrhosis [9]. So, we aimed to assess portal hemodynamics changes in hyponatremic Egyptian cirrhotic patients.

\section{PATIENTS AND METHODS}

This case control study was performed in Tropical Medicine Department Zagazig University Hospitals in the period between October 2017 and June 2019. A hundred and sixty patients were included in this study 125 males and 35 females with age ranging from 35 to 73 years old.

Patients below18 years or didn't give informed consent to participate in the study, those receiving direct acting antiviral drugs (DAAs) for $\mathrm{HCV}$ within 6 months, patients with hepatocellular carcinoma and other malignancy, patients with history of cardiac or renal diseases or non-viral causes of cirrhosis, patients with history of drugs, procedure, operation or condition that affect portal hemodynamics e.g. TIPS or shunt operation or portal vein thrombosis were excluded from the study.

The patients gave an informed consent and were divided according to their sodium level into: Group I: 80 hyponatremic patients with serum $\mathrm{Na}<130 \mathrm{mmol} / \mathrm{L}$, and group II: 80 nonhyponatremic patients with serum $\mathrm{Na}>130 \mathrm{mmol} / \mathrm{L}$.

All patients were subjected to full history taking, thorough clinical examination, full laboratory investigations: including liver function and prothrombin time (PT), kidney functions, complete blood picture (CBC), viral markers: HBsAg and HCV Ab, fasting blood glucose, markers of autoimmune liver diseases (ANA, ASMA, LKMA, AMA), serum sodium, potassium, chloride levels measurement by $\mathrm{mEq} / \mathrm{L}$ and calcium $\mathrm{mg} / \mathrm{dl}$. Modified Child, MELD and MELD Na score were calculated for all patients, Upper Gastrointestinal endoscopy and abdominal ultrasonography with Doppler US was performed.

\section{Statistical Analysis}

Data were analyzed with SPSS for version 25 (statistical package for the Social Science, Chicago, IL). Quantitative data were expressed as mean \& standard deviation (SD), normally distributed data were analyzed by independent sample $\mathrm{t}$ test and abnormally distributed data were analyzed by Mann Whitney test. While qualitative data were expressed as number and percentage and were analyzed by Chi square (X2) test. Correlation was done using Pearson correlation test. The receiver operating characteristic (ROC) curve and 95\% confidence interval (CI) was performed to determine cutoff values for different studied parameters. Sensitivity, specificity, positive predictive value (PPV) and negative predictive value (NPV) were determined. P-value was considered significant if $<0.05$ and highly significant if $<0.001$.

\section{RESULTS}

Patients' characteristics were represented in table (1). Serum sodium level has a highly statistically significant negative correlation with modified Child-Pugh score (a) $(\mathrm{r}=-0.400, \mathrm{P}<0.001)$ and with MELD score (b) $(r=-0.394, \mathrm{P}<0.001)$, Fig (1). Also, Serum sodium had a statistically significant positive correlation with mean PV velocity (a) $(\mathrm{r}=0.252, \mathrm{p}=0.001)$ and a highly statistically significant negative correlation with Mean flow volume (b), Portal vein CI (c) and hepatic A RI (d) ( $r=-0.593, r=-0.477$ and, $r=$ 0.490 respectively with $p<0.001$ for all), Fig (2). The difference in MELD score, MELD-Na score, portal vein CI and Hepatic A. RI between non survived and survived patients was statistically insignificant in both groups. The same results were found as regard complications with the exception MELD score, MELD-Na score in patients with hepatic encephalopathy and patients without hepatic encephalopathy had high statistically significant in both groups mean while PV CI and hepatic A RI was high statistically significant in hyponatremic group only, table (2). Analysis of the receiver operating characteristic (ROC) curve was performed to determine the prognostic validity at cutoff values for different studied parameters, Fig $(3,4)$, table (3). 
Table 1: Patients characteristics

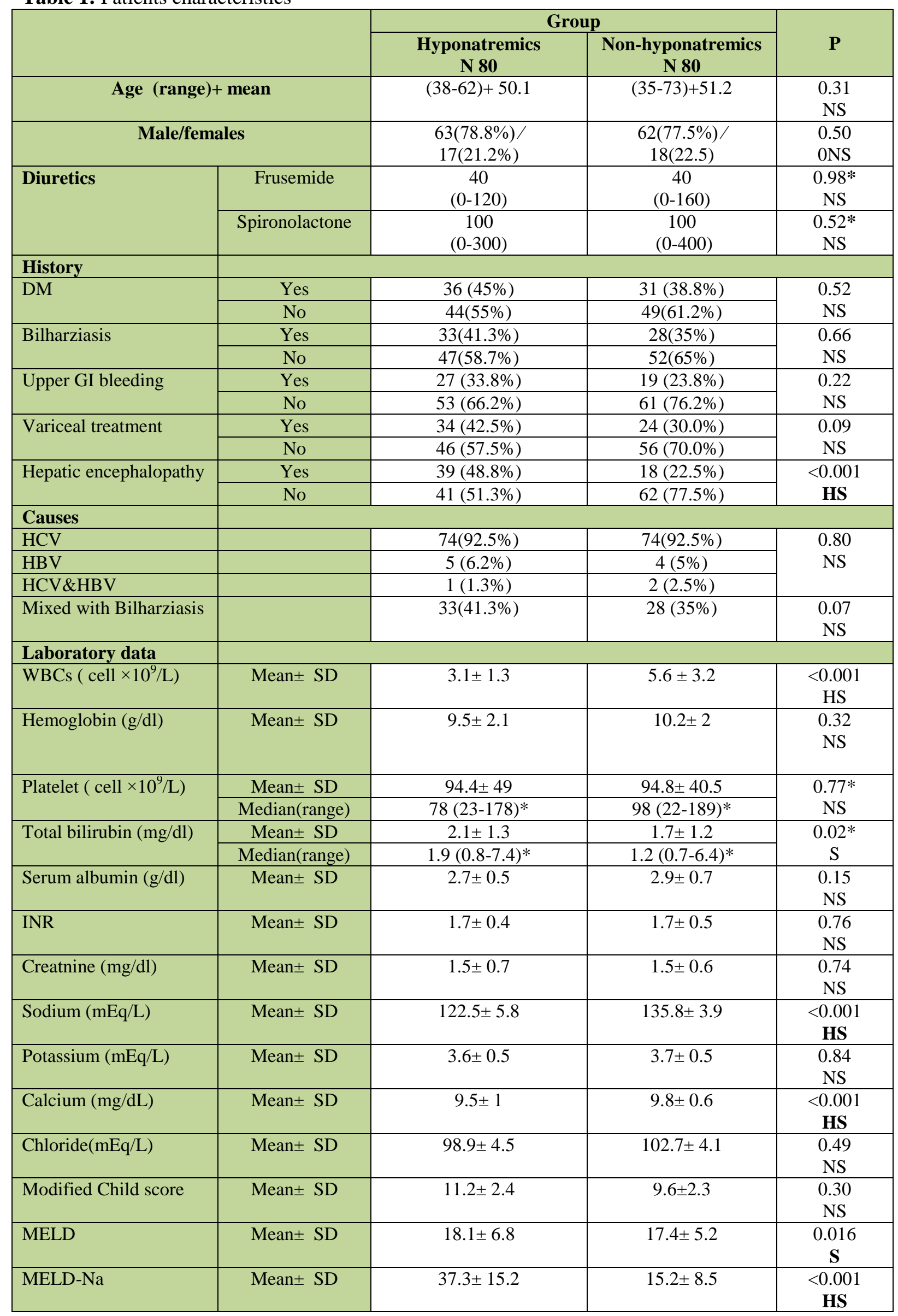

Awwaad et al., Afro-Egypt J Infect Endem Dis 2019; 9(4):260-269

https://aeji.journals.ekb.eg/

http://mis.zu.edu.eg/ajied/home.aspx 


\begin{tabular}{|c|c|c|c|c|}
\hline $\begin{array}{l}\text { Abdominal Ultrasono- } \\
\text { graphy with Doppler }\end{array}$ & & & & \\
\hline \multirow[t]{3}{*}{ Liver } & Average & $17(21.3 \%)$ & $26(32.5 \%)$ & \multirow{3}{*}{$\begin{array}{l}0.19 \\
\text { NS }\end{array}$} \\
\hline & Enlarged & $8(10 \%)$ & $10(12.5 \%)$ & \\
\hline & Shrunken & $55(68.7 \%)$ & $44(55 \%)$ & \\
\hline PV diameter(cm) & $\begin{array}{l}\text { Mean } \pm \text { Std. } \\
\text { Deviation }\end{array}$ & $1.6 \pm 0.23$ & $1.5 \pm 0.22$ & $\begin{array}{l}0.56 \\
\text { NS }\end{array}$ \\
\hline \multirow{2}{*}{ Splenomegaly } & Average & $7(8.8 \%)$ & $17(21.3 \%)$ & 0.02 \\
\hline & Echo_enlarged & $73(91.2 \%)$ & $63(78.7 \%)$ & $\mathbf{S}$ \\
\hline \multirow[t]{2}{*}{ Collaterals } & No & $23(28.7 \%)$ & $52(65 \%)$ & \multirow{2}{*}{$\begin{array}{l}<0.001 \\
\text { HS }\end{array}$} \\
\hline & Yes & $57(71.3 \%)$ & $28(35 \%)$ & \\
\hline \multirow[t]{2}{*}{ Ascites } & No & $7(8.2 \%)$ & $19(23.8 \%)$ & \multirow{2}{*}{$\begin{array}{c}0.009 \\
\mathbf{S}\end{array}$} \\
\hline & Yes & $73(91.3 \%)$ & $61(76.2 \%)$ & \\
\hline \multirow{2}{*}{$(\mathrm{OV})$} & No & $15(18.7)$ & $35(43.7)$ & \multirow{2}{*}{$\begin{array}{l}<0.001 \\
\text { HS }\end{array}$} \\
\hline & Yes & $65(81.3 \%)$ & $45(56.3 \%)$ & \\
\hline \multirow[t]{2}{*}{ (PHG) } & No & $30(37.5 \%)$ & $44(55 \%)$ & \multirow{2}{*}{$\begin{array}{l}<0.001 \\
\text { HS }\end{array}$} \\
\hline & Yes & $50(62.5 \%)$ & $36(45 \%)$ & \\
\hline PV mean velocity $(\mathrm{cm} / \mathrm{s})$ & Mean \pm SD & $10.6 \pm 2.8$ & $10.5 \pm 2.4$ & $\begin{array}{l}0.16 \\
\text { NS }\end{array}$ \\
\hline $\begin{array}{ll}\begin{array}{l}\text { Mean } \\
\text { volume }(\mathrm{ml} / \mathrm{min})\end{array} & \text { flow }\end{array}$ & Mean \pm SD & $960.1 \pm 232.9$ & $848.9 \pm 180.1$ & $\begin{array}{c}0.01 \\
\mathbf{S}\end{array}$ \\
\hline \multirow[t]{2}{*}{ Direction of flow } & Hepatopedal & $9(11.3 \%)$ & $48(60.0 \%)$ & \multirow{2}{*}{$\begin{array}{l}<0.001 \\
\text { HS }\end{array}$} \\
\hline & Hepatofugal & $71(88.8 \%)$ & $32(40.0 \%)$ & \\
\hline PV CI & Mean \pm SD & $0.093 \pm .019$ & $0.088 \pm .015$ & $\begin{array}{c}0.01 \\
\mathbf{S}\end{array}$ \\
\hline Hepatic A RI & Mean \pm SD & $0.78 \pm 0.072$ & $0.72 \pm 0.11$ & $\begin{array}{c}<0.001 \\
\text { HS }\end{array}$ \\
\hline \multicolumn{5}{|l|}{$\begin{array}{ll}\text { Morbidity } & \& \\
\text { Mortality } & \end{array}$} \\
\hline \multirow[t]{2}{*}{ (SBP) } & No & $47(58.8 \%)$ & $62(77.5 \%)$ & \multirow{2}{*}{$\begin{array}{c}0.009 \\
\mathbf{S}\end{array}$} \\
\hline & Yes & $33(41.2 \%)$ & $18(22.5 \%)$ & \\
\hline \multirow[t]{2}{*}{ (HRS) } & No & $60(75.0 \%)$ & $72(90.0 \%)$ & \multirow{2}{*}{$\begin{array}{c}0.01 \\
\mathbf{S}\end{array}$} \\
\hline & Yes & $20(25.0 \%)$ & $8(10.0 \%)$ & \\
\hline \multirow[t]{2}{*}{ Bleeding OV } & No & $66(82.5 \%)$ & $71(88.8 \%)$ & \multirow{2}{*}{$\begin{array}{c}0.15 \\
\text { NS }\end{array}$} \\
\hline & Yes & $14(17.5 \%)$ & $9(11.2 \%)$ & \\
\hline \multirow[t]{2}{*}{ Hepatic encephalopathy } & No & $36(45.0 \%)$ & $61(76.2 \%)$ & \multirow{2}{*}{$\begin{array}{l}<0.001 \\
\text { HS }\end{array}$} \\
\hline & Yes & $44(55.0 \%)$ & $19(23.8 \%)$ & \\
\hline \multirow[t]{2}{*}{ Death } & No & $72(90 \%)$ & $77(96.3 \%)$ & \multirow{2}{*}{$\begin{array}{c}0.006 \\
\mathbf{S}\end{array}$} \\
\hline & Yes & $8(10 \%)$ & $3(3.8 \%)$ & \\
\hline
\end{tabular}

Median (range) *Mann-Whitney test *

NB: In upper GIT endoscopy there was no patients with gastric varices either solitary or combined with OV.

Diabetes Mellitus (DM), Hepatitis C Virus (HCV), Hepatitis B Virus (HBV), combined hepatitis C and $\mathrm{B}$ viruses (HCV\&HBV), White Blood Cells (WBCs), International Normalized Ratio (INR), Model for End-Stage Liver Disease (MELD), MELD sodium (MELD-Na), Portal Vein (PV), Oesophageal varices ( OV), Portal Hypertensive Gastropathy (PHG), Portal Vein Congestive Index (PV CI), Hepatic Artery Resistive Index (Hepatic A RI), Spontaneous Bacterial Peritonitis (SBP), Hepatorenal Syndrome (HRS) 
Figure 1: Correlation between serum sodium and modified Child-Pugh score and MELD score:

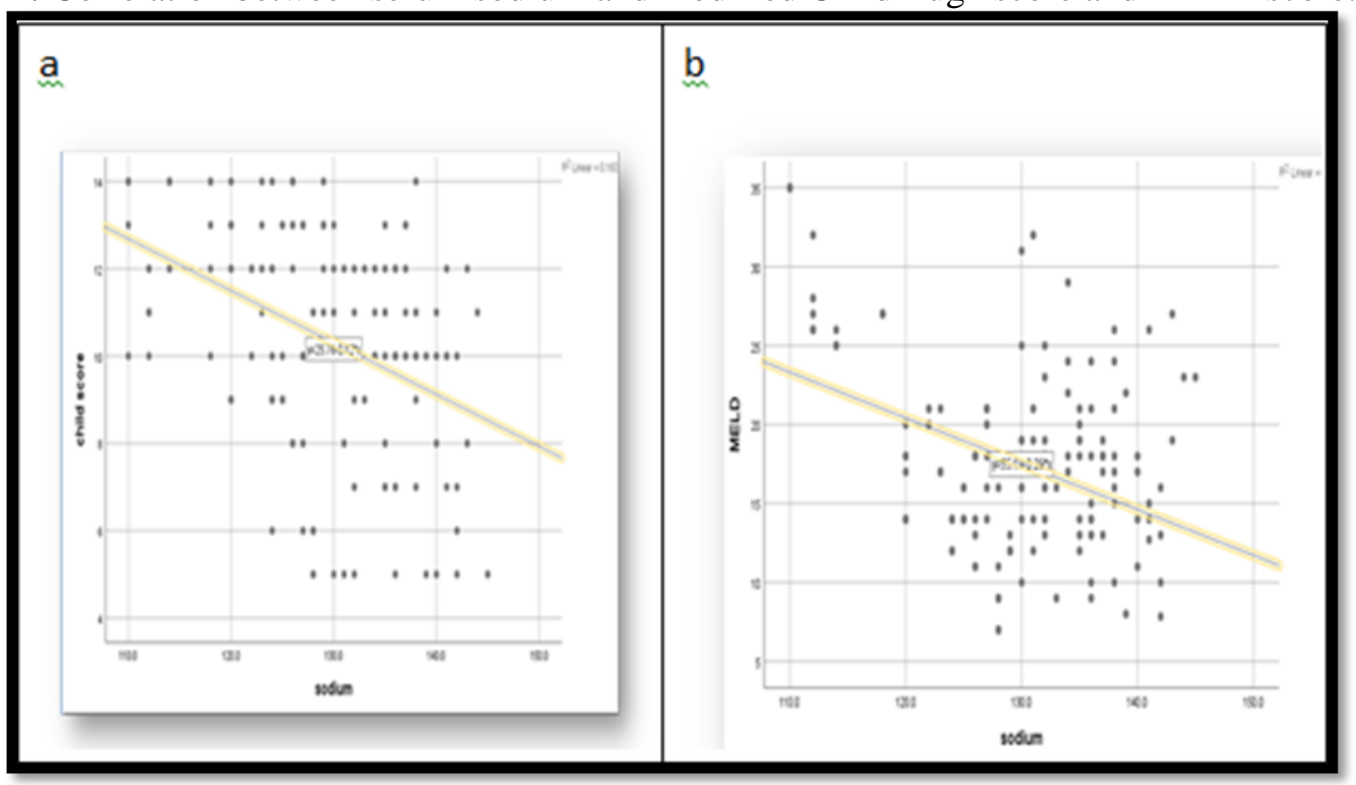

Serum sodium level has a highly statistically significant negative correlation with modified ChildPugh score (a) ( $\mathrm{r}=-0.400, \mathrm{P}<0.001)$ and with MELD score (b) $(\mathrm{r}=-0.394, \mathrm{P}<0.001)$.

Figure (2): Correlation between serum sodium and portal hemodynamics in Doppler US:
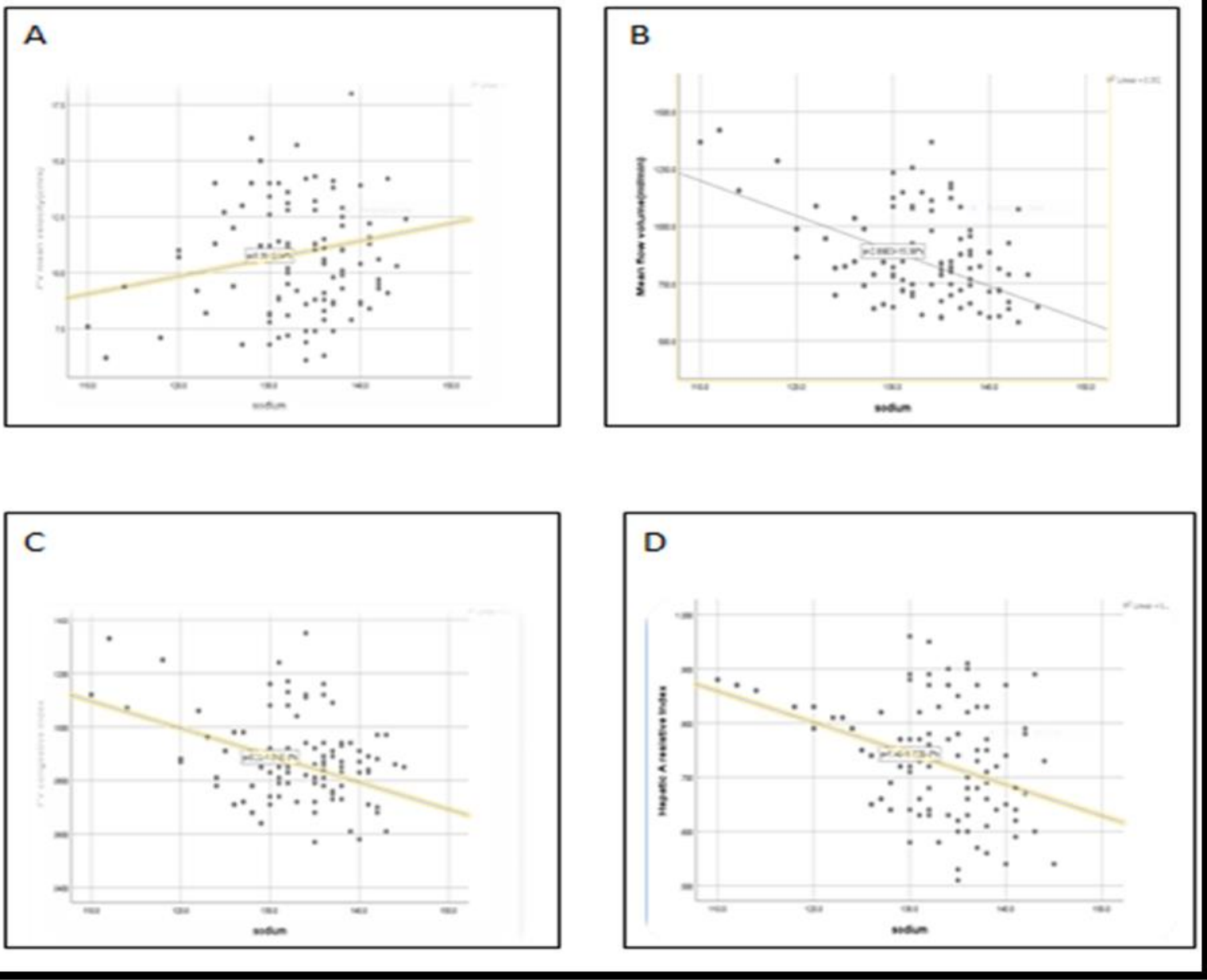

Serum sodium had a statistically significant positive correlation with mean PV velocity (a) $(r=0.252$, $\mathrm{p}=0.001)$ and a highly statistically significant negative correlation with Mean flow volume (b), Portal vein CI (c) and hepatic A RI (d) $(r=-0.593, r=-0.477$ and, $r=-0.490$ respectively with $p<0.001$ for all). 
Table 2: MELD score, MELD-Na score, portal vein CI and Hepatic A RI among both groups as regard survival and different complication

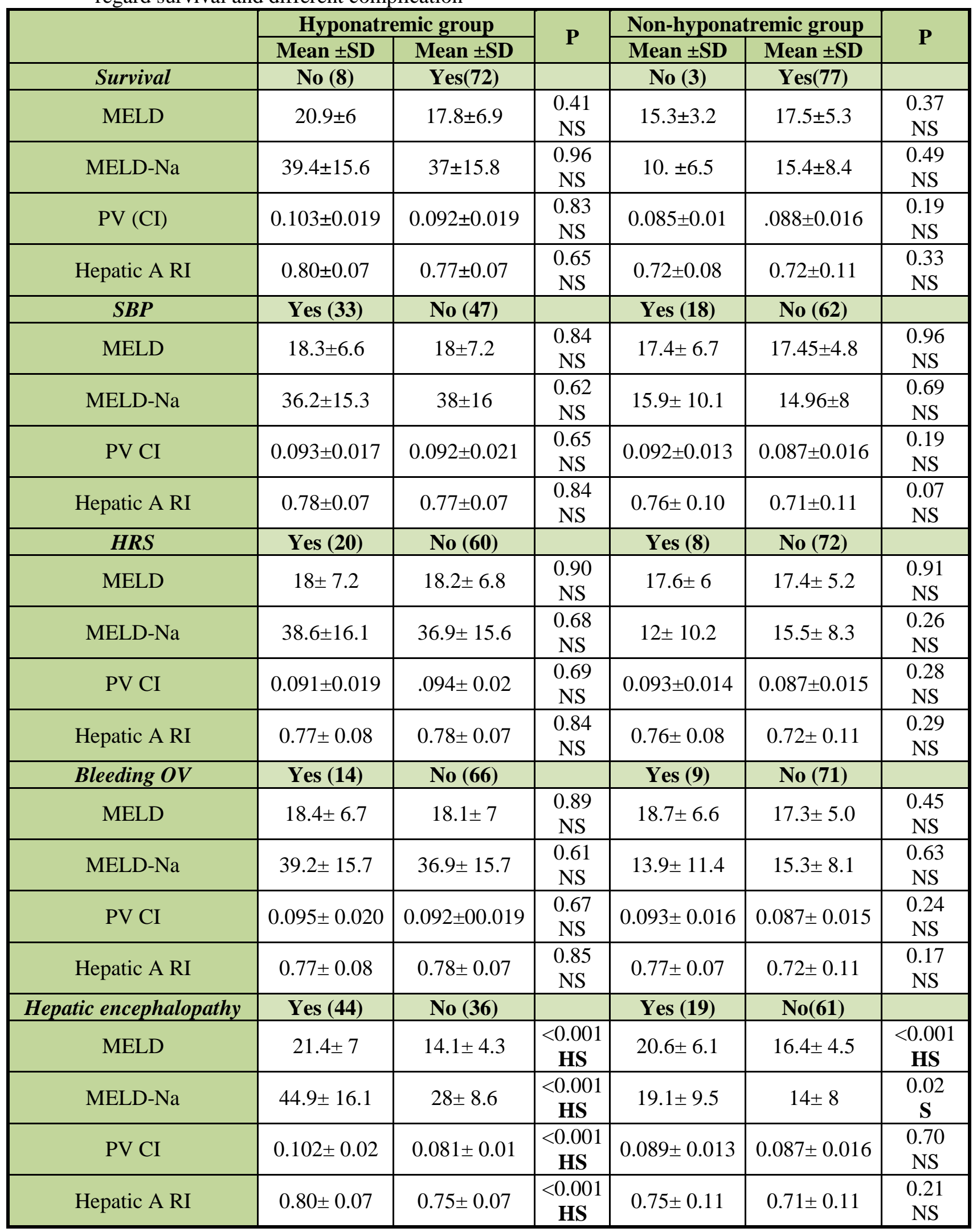

Model for End-Stage Liver Disease (MELD), MELD sodium (MELD-Na), Portal Vein (PV), Oesophageal varices ( OV), Portal Hypertensive Gastropathy (PHG), Portal Vein Congestive Index (PV CI), Hepatic Artery Resistive Index (Hepatic A RI), Spontaneous Bacterial Peritonitis (SBP), Hepatorenal Syndrome (HRS) 
Figure 3: The receiver operating characteristic (ROC) curve of MELD score, MELD-Na, portal vein CI and Hepatic A RI as predictors for mortality in hyponatremia patients

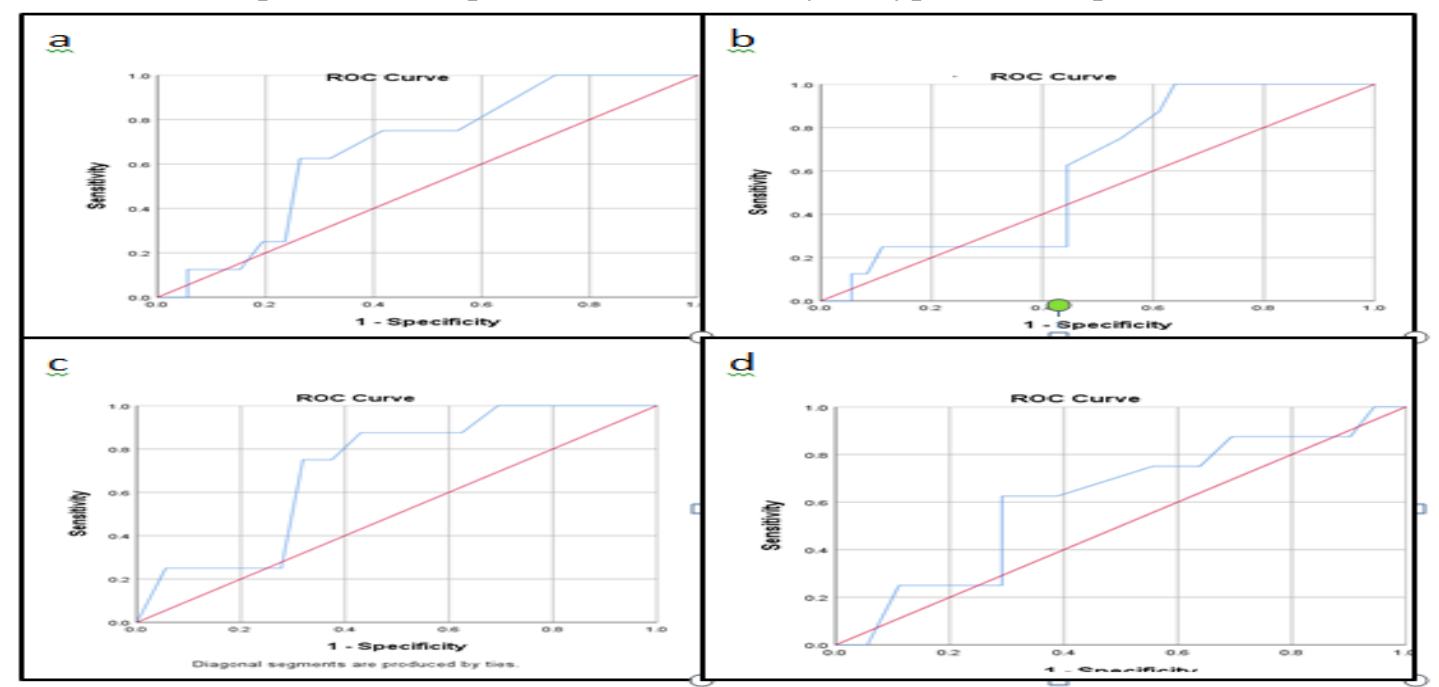

Area under the ROC curve of the studied parameters was as the following: MELD score (a) was 0.670 (0.51-0.83), MELD-Na score (b) was 0.602 (0.44-0.76), portal vein CI (c) was 0.711(0 .56-0.86) while Hepatic A. RI. (d) was $0.712(0.410-0.814)$.

Figure 4:The receiver operating characteristic (ROC) curve of MELD score, MELD-Na, portal vein $\mathrm{CI}$ and Hepatic A. RI. as predictors for hepatic encephalopathy in hyponatremia patients:

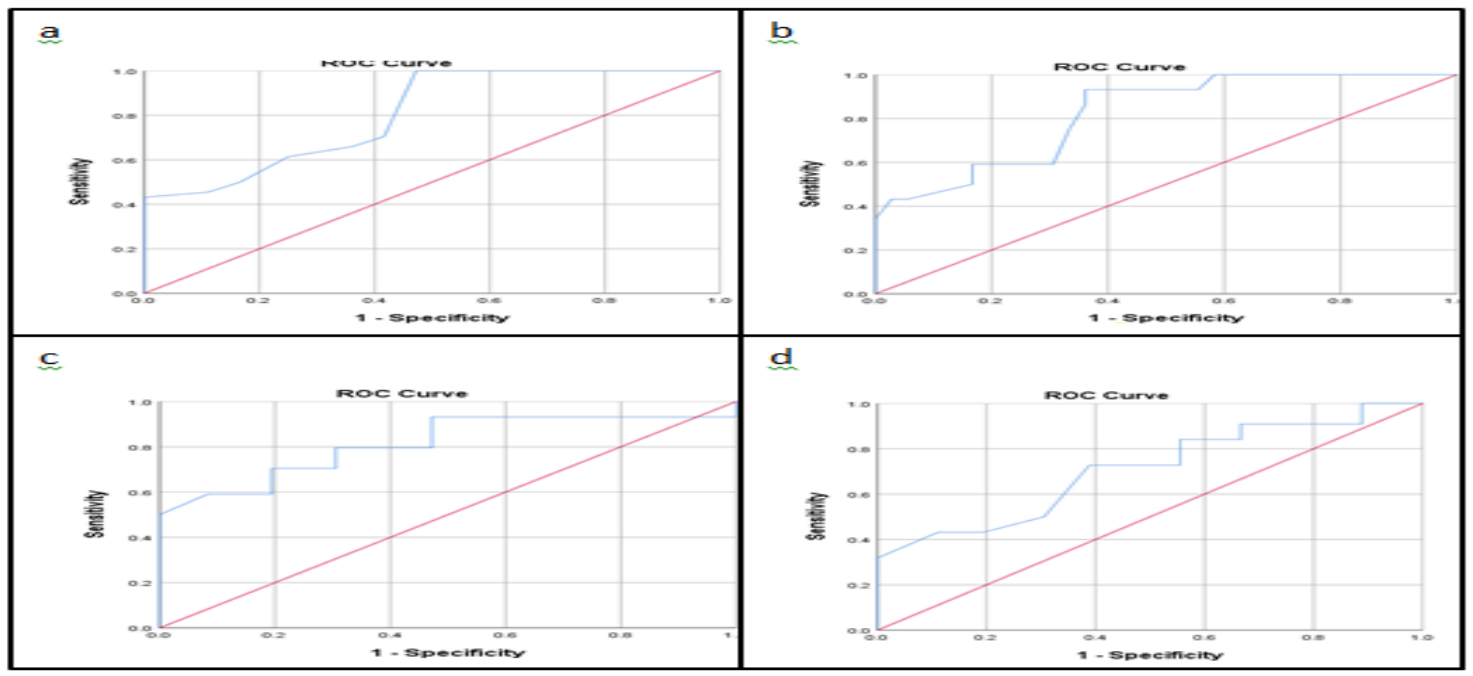

Area under the ROC curve of the studied parameters was as the following:

MELD score (a) was 0.806 (0.71-0.90), MELD-Na score (b) was 0.822 (0.73-0.91), portal vein CI (c) was 0.7814(0.72-0.91) while Hepatic A. RI. (d) was 0.708 (0.60-0.82). 
Table 3: The validity of MELD, MELD-Na, portal vein CI and Hepatic A. RI as a predictor factor for mortality and hepatic encephalopathy in hyponatremia patient

\begin{tabular}{|c|c|c|c|c|c|}
\hline Parameter & Cut-off value & Sensitivity & Specificity & PPV & NPV \\
\hline \multicolumn{5}{|c|}{ Mortality } \\
\hline MELD & 21 & $62.5 \%$ & $68.1 \%$ & 50 & 54.5 \\
\hline MELD-Na & 32 & $62.5 \%$ & $56 \%$ & 50 & 44.8 \\
\hline PV CI & 0.089 & $78.5 \%$ & $56.5 \%$ & 62.8 & 45.4 \\
\hline Hepatic A RI & 0.82 & $63 \%$ & $70.8 \%$ & 50.4 & 56.6 \\
\hline \multicolumn{7}{|c|}{ Hepatic encephalopathy } \\
\hline MELD & 18 & $61.4 \%$ & $75 \%$ & 49.1 & 60 \\
\hline MELD-Na & 31 & $75 \%$ & $66.7 \%$ & 60 & 53.4 \\
\hline PV CI & .097 & $59.1 \%$ & $91.7 \%$ & 47.3 & 73.4 \\
\hline Hepatic A RI & .78 & $72.7 \%$ & $69.4 \%$ & 58.2 & 55.5 \\
\hline
\end{tabular}

Model for End-Stage Liver Disease (MELD), MELD sodium (MELD-Na), Portal Vein (PV), Portal Vein Congestive Index (PV CI), Hepatic Artery Resistive Index (Hepatic A RI), Spontaneous Bacterial Peritonitis (SBP), Hepatorenal Syndrome (HRS).

At cut off values of MELD score $>21$, MELD-Na score $>32$ PV congestive index $>0.089$ and hepatic A resistive Index $>0.82$. Portal vein CI was the most sensitive indicator and hepatic A RI was the most specific indicator for prediction of mortality in hyponatremia patients. While MELD-Na score was the most sensitive indicator and PV CI was the most specific indicator for prediction of hepatic encephalopathy in hyponatremia patients, at cut off values of MELD score $>18$, MELD-Na score $>31$ $\mathrm{PV}$ congestive index $>0.097$ and hepatic A resistive Index $>0.78$.

\section{DISCUSSION}

Cirrhosis has various degrees of liver dysfunction and portal hemodynamics disturbances. Hyponatremia is the most common electrolyte defect in advanced cirrhotic patients and indicates a poor prognosis $[2,3]$. Doppler ultrasound (US) allows a safe, cheap and efficient real-time observation of blood flow of portal circulation in cirrhotic patients. The aim of our study was to investigate this relationship between hyponatermia and portal hemodynamic parameters obtained by Doppler US .

We found that serum sodium level significantly decreased with the advance of Child-Pugh score and with MELD score $(r=-0.400, r=-0.394$ and $P$ value $<0.001$ ) and this was in line with Angeli $p$ et al., Kim J et al., Reddy et al.,[10 ,11 12]. Hyponatremia signifies an independent predictor for the development of complications in cirrhotic patients and adding serum sodium to MELD score improves prediction of short-term mortality amongst candidates for liver transplantation [13].

In the current study, hyponatremic had a statistically significant difference when compared with non-hyponatremic group in the presence of splenomegaly and ascites and high statistically significant difference as regard collaterals. These results were similar to those of Angeli et al., Kim et al., and Maruyama et al.,[10, 11, 14] and as regard ascites and collaterals but was not as regard splenomegaly as Maruyama et al., $[\mathbf{9 , 1 4}]$ stated no relation between hyponatermia and splenic size, also, Reddy et al., [12] reported significant difference only in refractory ascites. Some authors specify that hyponatremia denotes parenchymal affection and others postulate that it denotes mesenchymal affection with close relation to portal hemodynamics.

Abdominal Doppler UltraSonographic data of both groups revealed that hyponatremic patients had no statistically significant difference in mean velocity and had statistically significant increases in mean flow volume and PV congestive index (PV CI), in addition to high statistically significant increases in hepatic artery resistive index (hepatic A RI) and reversal of direction of blood flow when compared with the non-hyponatremic group. Maruyama et al., $[9,14]$ had the same results about PV mean velocity and collaterals but had not the same of our opinion about mean flow volume and direction of flow as they did not find any significance in hyponatremic patients. Okazakiet et al., [15] reported a significant decrease in portal blood flow volume in cirrhotic patients, while Ohnishi et al., [16] found a significant increase as we found. This controversy could be explained by different patient characteristics as in our study, the direction of flow and presence of collaterals may affect flow volume and PV mean velocity as most of the portal flow is 
diverted through portosystemic collateral vessels. The decrease in portal perfusion is to some extent buffered by an increase of arterial perfusion, which is, however, not enough to restore the normal liver perfusion [17].

We found that serum sodium level had a statistically significant mild positive correlation with PV mean velocity $(r=0.252, p=0.001)$ and a highly statistically significant negative correlation with Mean flow volume, Portal vein CI and hepatic A RI $(r=-0.593, r=-0.477$ and, $r=-0.490)$. Splanchnic arterial vasodilatation with reduced systemic vascular resistance leads to reduced mean arterial pressure. It is sensed by baroreceptor and causes activation of compensatory neurohormonal mechanisms, which include renin-aldosteroneangiotensin system, the sympathetic nervous system and, as well as the release of antidiuretic hormone with stimulation of retention of solutefree water, avid renal sodium retention, and dilutional hyponatremia. These compensatory neurohormonal mechanisms correlate directly with the degree of portal hypertension. Therefore, serum sodium could be a reasonable parameter that reflects the severity of portal hypertension [18].

Most of our hyponatremic patients developed hepatic encephalopathy, SBP and HRS, also, mortality was reported more in this group with statistically significant difference when compared to non hyponatremic group, while, there was no statistically significant difference as regard bleeding OV when they compared with nonhyponatremic ones. Our results go in hand with that of Angeli $\mathrm{p}$ et al., Kim $\mathrm{J}$ et al., Reddy et al., Amalan et al., [10,11 12, 19] except for HRS in which Kim et al., [11] did not find significant relationship and in bleeding OV in which Amalan et al., [19] reported significant relationship between hyponatermia and bleeding varices. Intervention at various levels of the disease (either improving the microcirculation or the liver's response to damage) can cause improvements in $\mathrm{PH}$ and its complications [20].

In the present study, the difference in MELD score, MELD-Na score, portal vein CI and Hepatic A. RI. between non survived and survived patients was statistically insignificant in both groups. Also, the difference in MELD score, MELD-Na score, portal vein $\mathrm{CI}$ and Hepatic A. RI between patients with complication (SBP, HRS and bleeding OV) and those without was statistically insignificant in both groups. This could provide new insights on unusual targetable molecular pathways and metabolites that may affect the outcome in such patients [20]. In addition, our study revealed high statistically significant difference in MELD score, MELD-Na score between patients complicated with hepatic encephalopathy and those without in both groups and high statistically significant difference in PV congestive index and hepatic A RI in hyponatremic group only. At advanced stages of liver cirrhosis, portal hypertension causes atrophy of the right lobe of the liver and the left lobe hypertrophy. The volume of the liver is directly related to hepatic function and the patient's prognosis . The volume of the right lobe represents two-thirds of the total hepatic volume; so, it is important to prevent right hepatic lobe atrophy in order to improve liver function in patients with cirrhosis and portal hypertension [21].

Validity of MELD, MELD-Na, portal vein CI and Hepatic A. RI in the present study as a predictor factor for mortality and hepatic encephalopathy in hyponatremic patients revealed that portal vein CI at cut off value $<0.089$ was the most sensitive indicator (Sensitivity was 78.5\%) and hepatic A RI cut off value $<0.82$ was the most specific indicator (Specificity was $70.8 \%$ ) for prediction of mortality while MELD-Na score at cut off value $<31$ was the most sensitive indicator (Sensitivity was $75 \%$ ) and PV CI at cut off value 0.097 was the most specific indicator (Specificity was 91.7\%) for prediction of hepatic encephalopathy.

In cirrhosis, hyponatremia usually develops in a slow and gradual manner. So, the brain can acclimatize to hypotonicity and hypo-osmolality of the extracellular fluid. However, due to the abnormalities in nitrogen metabolism, symptoms that are related to hyponatremia are usually concomitant with and hardly distinct from symptoms of hepatic encephalopathy [13]. Scores obtained by the combinations of measuring portal vein blood velocity, portal vein diameter, the hepatic artery resistance index and splenic artery resistance index were planned and demonstrated to be useful in the clinical monitoring of patients with portal hypertension and cirrhosis [22].

\section{Conclusion:}

Hyponatremic patients had statistically significant increase in mean flow volume and PV congestive index, in addition to highly statistically significant increase in hepatic artery resistive index and reversal of direction of blood flow. Most of hyponatremic patients developed Hepatic encephalopathy, SBP and HRS, also, mortality was reported more in this group with statistically 
significant difference when compared with nonhyponatremia group. Moreover we can use MELD$\mathrm{Na}$ score, portal vein CI and hepatic A RI. in prediction of hepatic encephalopathy and mortality in hyponatermic patients.

Ethical consideration: Approval was taken from ethical committee (IRB: ZU-IRB\#2927) also ethical consent was taken from persons included in the study.

\section{Funding:Non.}

Conflict of interest: There was no conflict of interest.

\section{REFERENCES}

1. Tsochatzis EA, Bosch J, Burroughs AK. Liver cirrhosis. The Lancet. 2014 May 17; 383(9930):1749-61.

2. Ginès $P$ and Guevara $M$. Hyponatremia in cirrhosis: pathogenesis, clinical significance, and management. Hepatology. 2008 Sep; 48(3):100210 .

3. Ahluwalia V, Heuman DM, Feldman G, Wade JB, Thacker LR, Gavis E et al,. Correction of hyponatraemia improves cognition, quality of life, and brain oedema in cirrhosis. Journal of hepatology. 2015 Jan 1; 62(1):75-82.

4. Adrogué HJ and Madias NE. Hyponatremia. New England Journal of Medicine. 2000 May 25; 342(21):1581-9.

5. Gianotti RJ, Cardenas A. Hyponatraemia and cirrhosis. Gastroenterology report. 2014 Feb 1; 2(1):21-6.

6. Sanyal AJ, Bosch J, Blei A, Arroyo V. Portal hypertension and its complications. Gastroenterolog. 2008 May 1; 134(6):1715-28.

7. Bolondi LU, Gaiani S, Barbara L. Doppler flowmetry in portal hypertension. In Innovations in Abdominal Ultrasound.1992 (pp. 49-60). Springer,Berlin, Heidelberg.

8. Baik SK. Haemodynamic evaluation by Doppler ultrasonography in patients with portal hypertension: a review. Liver International. 2010 Nov; 30(10):1403-13.

9. Maruyama H, Kondo T, Kiyono S, Sekimoto T, Takahashi M, Okugawa $\mathrm{H}$ et al,. Relationship and interaction between serum sodium concentration and portal hemodynamics in patients with cirrhosis. Journal of gastroenterology and hepatology. 2015 Nov; 30(11):1635-42.

10. Angeli P, Wong F, Watson H, Ginès P, Capps Investigators. Hyponatremia in cirrhosis: results of a patient population survey. Hepatology. 2006 Dec; 44(6):1535-42.

11. Kim JH, Lee JS, Lee SH, Bae WK, Kim NH, Kim KA et al,. The association between the serum sodium level and the severity of complications in liver cirrhosis. The Korean journal of internal medicine. 2009 Jun; 24(2):106.

12. Reddy D.Dinesh Kumar, Sarma C.S.S, Madhavi. Study of hyponatremia in cirrhosis of liver and its prognostic Value. Journal of medical science and clinical research JMSCR. 2019 March; 7(3): 487-493.

13. Bernardi M, Ricci C, Santi L. Hyponatremia in Patients with Cirrhosis of the Liver. Journal of clinical medicine. $2015 \mathrm{Jan}$; 4(1):85-101.

14. Maruyama H, Kondo T, Sekimoto T, Kiyono S, Shimada T, Takahashi M et al,. Hyponatremia: a significant factor in a poor prognosis for cirrhosis with Child A/B after variceal eradication. Journal of hepato-biliary-pancreatic Sciences. 2015 Oct; 22(10):771-8.

15. Okazaki K, Miyazaki M, Onishi S, Ito K. Effects of food intake and various extrinsic hormones on portal blood flow in patients with liver cirrhosis demonstrated by pulsed Doppler with the Octoson. Scandinavian journal of gastroenterology. 1986 Jan 1; 21(9):1029-38.

16. Ohnishi K, Sato S, Pugliese D, Tsunoda T, Saito M, Okuda K. Changes of splanchnic circulation with progression of chronic liver disease studied by echo-Doppler flowmetry. American journal of gastroenterology. 1987 Jun 1; 82(6.(

17. Annet L, Materne R, Danse E, Jamart J, Horsmans Y, Van Beers BE. Hepatic flow parameters measured with MR imaging and Doppler US: correlations with degree of cirrhosis and portal hypertension. Radiology. 2003 Nov; 229(2):409-14

18. Biggins SW, Rodriguez HJ, Bacchetti P, Bass NM, Roberts JP, Terrault NA. Serum sodium predicts mortality in patients listed for liver transplantation. Hepatology. 2005 Jan; 41(1):329.

19. Amalan Christudhas V, Ilakkiya Venu, Suhas Raj Sivakumar, Silambarasan. Clinical Study of Association between the Serum Sodium level and Severity of complication in Liver Cirrhosis at Kanyakumari government medical college. Int. J. Adv. Res.2018 Oct; 6(10), 369-374.

20. Vilaseca M, Guixé-Muntet S, Fernández-Iglesias A, Gracia-Sancho J. Advances in therapeutic options for portal hypertension. Therapeutic advances in gastroenterology. 2018 Nov; 11:1756284818811294.

21. Li X, Wang XK, Chen B, Pu YS, Li ZF, Nie P, et al,. Computational hemodynamics of portal vein hypertension in hepatic cirrhosis patients. Biomedical materials and engineering. 2015 Jan 1; 26(s1):S233-43

22. Bolognesi M, Di Pascoli M, Sacerdoti D. Clinical role of non-invasive assessment of portal hypertension. World journal of gastroenterology. 2017 Jan 7; 23(1):1. 